\title{
Incidents reporting: barriers and strategies to promote safety culture*
}

\author{
Notificação de incidentes: barreiras e estratégias para promover a cultura de segurança \\ Notificación de incidentes: barreras y estrategias para promover la cultura de seguridad
}

Fabiana Rossi Varallo', Aline Cristina Passos' ${ }^{1}$, Tales Rubens de Nadai ${ }^{2}$, Patricia de Carvalho Mastroianni' ${ }^{1}$

How to cite this article:

Varallo FR, Passos AC, Nadai TR, Mastroianni PC. Incidents reporting: barriers and strategies to promote safety culture. Rev Esc Enferm USP. 2018;52:e03346. DOI: http://dx.doi.org/10.1590/S1980-220X2017026403346

${ }^{*}$ Extracted from the final work: "Causas de subnotificação a eventos adversos no Hospital Estadual Américo Brasiliense”, Curso de Especialização em Saúde Pública, Faculdade de Ciências Farmacêuticas, Universidade Estadual Paulista, 2014.

${ }^{1}$ Universidade Estadual Paulista, Faculdade de Ciências Farmacêuticas, Campus Araraquara, Araraquara, SP, Brazil.

${ }^{2}$ Hospital Estadual Américo Brasiliense, Departamento de Cirurgia e Anatomia, Faculdade de Medicina de Ribeirão Preto, Universidade de São Paulo, Ribeirão Preto, SP, Brazil.

\section{ABSTRACT}

Objective: The purpose was to identify the barriers of underreporting, the factors that promote motivation of health professionals to report, and strategies to enhance incidents reporting. Method: Group conversations were carried out within a hospital multidisciplinary team. A mediator stimulated reflection among the subjects about the theme. Sixty-five health professionals were enrolled. Results: Complacency and ambition were barriers exceeded. Lack of responsibility about culture of reporting was the new barrier observed. There is a belief only nurses should report incidents. The strategies related to motivation reported were: feedback; educational intervention with hospital staff; and simplified tools for reporting (electronic or manual), which allow filling critical information and traceability of management risk team to improve the quality of report. Conclusion: Ordinary and practical strategies should be developed to optimize incidents reporting, to make people aware about their responsibilities about the culture of reporting and to improve the risk communication and the quality of healthcare and patient safety.

\section{DESCRIPTORS}

Drug-related Side Effects and Adverse Reactions; Attitude of the Health Personnel; Patient Safety; Safety Management; Adverse Drug Reaction Reporting Systems; Pharmacovigilance.
Corresponding author:

Patricia de Carvalho Mastroianni

Universidade Estadual Paulista, Faculdade de

Ciências Farmacêuticas, Campus Araraquara

Rodovia Araraquara-Jaú, Km

1, s/n, Campus Ville

CEP 14800-903 - Araraquara, SP, Brazil

patriciamastroianni@yahoo.com.br
Received: 07/12/2017

Approved: 01/31/2018 


\section{INTRODUCTION}

Incident reporting is the main method of generating alert signals concerning the provision of quality healthcare ${ }^{(1-2)}$. However, only $1 \%$ of incidents are reported by health professionals $s^{(3)}$. The lack of information contributes to low effectiveness of surveillance ${ }^{(4)}$ and increases bias in epidemiologic communication ${ }^{(5)}$. This limits the development of safety measures.

The reasons for underreporting are lack of time, unbelief in improvement, fear of reprisal ${ }^{(3)}$, and that the observed event has not caused serious harm to the patient ${ }^{(6)}$. A systematic review ${ }^{(7)}$ also showed that lack of knowledge is a reason for underreporting of adverse drug events (ADEs). The authors suggested a need for qualitative research to assess the perception of health professionals related to the barriers of risk communication, as well as educational intervention to increase awareness about the risk management services.

A multidisciplinary approach to drug-safety assessments carried out in a general public hospital contributed to identifying new, relevant drug-related problems and improved the number of $\mathrm{ADE}$ reports by $70-\mathrm{fold}^{(8)}$. However, $10.5 \%$ of adverse drug reactions remained unreported ${ }^{(9)}$. Therefore, it is important to encourage health professionals to report incidents in order to i) promote the identification of problems in a non-blaming manner, ii) enable self-assessment of healthcare practices, and iii) allow the development of new professional and institutional structures to define the responsibilities and standards for patient safety as well as prepare management policies such as risk minimization plans ${ }^{(1-2)}$. The present study aims to identify the causes related to the underreporting of incidents by health professionals, reasons that limit health professionals' motivations to make reports, and to propose strategies to increase the adherence of hospital care teams to risk management policies.

\section{METHOD}

\section{StUdi DESIGN}

With a technique of group of conversation, health professionals were invited to discuss their experiences, perceptions and behavior about the practice and process of incidents reporting. We applied the guideline RATS to perform the study ${ }^{(10)}$.

\section{SAMPLING AND LOCAL}

During the period of the study, the staff of hospital comprised 354 health professionals, who covered the follow wards: intensive care unit (ICU), infectious diseases, internal medicine and palliative care.

All health professionals were invited to participate of the groups of conversations. Each group was formed with at least one subject from each profession of a multidisciplinary health team, which comprises social workers, nutritionists, physiotherapists, psychologists, pharmacists, pharmacy technicians, speech therapists, occupational therapists, physicians, and nursing staff.

Ten groups of conversation were held during the three shifts, being four in the morning, four in the afternoon and two at night. Sixty-five volunteers were enrolled until the saturation of findings (when any new information was not observed or reported). Discussions occurred in a room between the wards, in order to facilitate the participation in the study.

\section{RECRUITMENT}

Invitation of all health professionals was carried out personally and up-to three times in each shift. Participation was voluntary and with the approval by the Board of Directors.

\section{Data collection}

Group of conversations was performed by three researchers with equal cultural competence and with experience in the issue (an expert in public health, a master and a $\mathrm{PhD}$ in Pharmaceutical Sciences). A mediator (ad hoc consulter with a University affiliation) developed the discussions, motivating the employees to express their perceptions about the "culture of reporting".

With the aid of three questions, issues related to barriers of reporting, what are the factors related to motivation for reporting and the strategies to improve reporting of incidents were discussed among the groups.

Researchers performed annotation of discourses according to information that represents the barriers related to reporting, the motivations and strategies to improve them.

\section{DATA ANALYSIS}

Barriers identified were classified according to seven causes of underreporting ${ }^{(11)}$ : i) complacency (believing that serious ADRs are well documented when the drug is released on the market); ii) fear of becoming involved in a lawsuit or legal process; iii) guilt for having been responsible for the damage observed in the patient; iv) ambition of the group to publish case series or benefit financially; v) ignorance of how to describe the reports (believing that only serious and unexpected ADEs must be reported); vi) insecurity about reporting suspicions of ADEs (belief that there should be reports only if there is certainty that the damage was caused by the use of specific medication); and vii) indifference due to lack of interest, time, or other excuses related to postponing the report of damage due to drug use.

Factors related to motivation and strategies to improve incidents reports were described according to the suggestions of health professionals.

\section{ETHICAL ASPECTS}

The study (protocol CAAE 35586714.8.0000.5426) was conducted in accordance with ethical statements of Ordinance 466/12. It was approved under the protocol number 956.833 in $02 / 09 / 2015$ by the Ethics Committee in Research of the School of Pharmaceutical Sciences of UNESP-Araraquara (SP), Brazil.

\section{RESULTS}

According to the perceptions of health professionals, the causes of underreporting incidents were indifference, diffidence, ignorance, and guilt for having been responsible for the incidents or for communicating them, whose coworker was the responsible (Chart 1 ). The barriers of complacency and ambition described previously ${ }^{(11)}$ were not observed. 
We noticed a new barrier related to the lack of accountability of health professionals related to the culture of reporting. There is a belief among them that just the nurse staff is responsible for reporting (Chart 1).

Chart 1 - Causes of underreporting according to the perceptions of health professionals from a public general hospital in the state of São Paulo, 2017.

\begin{tabular}{|c|c|}
\hline Causes & Perceptions \\
\hline GUILT & $\begin{array}{l}\text { There is a feeling of guilt for being responsible for the occurrence of an incident. Reports may indicate an inappropriate } \\
\text { practice during the healthcare procedures ("I could reveal inconsistencies). } \\
\text { Furthermore, professionals reported uncomfortable situations in reporting incidents by a coworker. The report would impair } \\
\text { the career of the colleague due to evidence of incompetence or negligence regarding institutional protocols ("I could reveal } \\
\text { the incompetence of my colleague with my report"). }\end{array}$ \\
\hline IGNORANCE & $\begin{array}{l}\text { Ignorance is related to incident reporting ("I do not know what or how to report", "I have no knowledge about what to } \\
\text { report", "I do not know where to find the reporting form", "I do not know where to send the reporting form", "I did not know } \\
\text { that the multidisciplinary team can file reports"). } \\
\text { Moreover, several professionals report only serious incidents ("I report just the most serious incidents for patients", "The } \\
\text { incident does not impact the patient in that moment, so I did not report it", "If we solve the non-serious incidents, we do not } \\
\text { report them"), since reporting process wastes time, and healthcare is a priority when compared with filling out documents } \\
\text { ("Pharmacovigilance and technical surveillance reporting forms have a lot of information. Even if they were mostly ordinary } \\
\text { incidents, we would have to take time to fill them out"). }\end{array}$ \\
\hline DIFFIDENCE & A lack of causal evidence also leads to underreporting ("I am not sure about which drug was responsible for the incident"). \\
\hline INDIFERRENCE & $\begin{array}{l}\text { The lack of feedback and the absence of the culture of reporting are important barriers ("Culturally, Brazilian professionals do } \\
\text { not file reports. I worked at another health institution and nobody filed reports there", "I do not know what happens with my } \\
\text { report", "I do not file reports because I do not see changes in my work routine"). } \\
\text { Complexity in filling out reporting forms is also a hindrance ("The reporting form is too long", "The reporting form gives me } \\
\text { more work"). Besides filling out the form, incidents must be registered in medical records and in an institutional document } \\
\text { ("We must report incidents twice, which wastes my time and I have other priorities"). }\end{array}$ \\
\hline $\begin{array}{l}\text { LACK } \\
\text { ACCOUNTABILITY }\end{array}$ & $\begin{array}{l}\text { Nursing staff has the responsibility to file reports ("I identify the incident and communicate it to the nurse", "Nursing staff } \\
\text { must fill out the reporting form"). Therefore, responsibility always belongs to another person. However, nursing staff does not } \\
\text { file reports because they are overworked and have no time ("My commute is six hours, but I must manage } 24 \text { hours. Even if } \\
\text { other professionals identify the incident, I will forget to report it"). }\end{array}$ \\
\hline
\end{tabular}

Source: Elaborated by the authors. Note: $(n=65)$.

The most frequent reason reported in association with the motivation of reporting was a lack of knowledge about the importance of incident reporting in generating indicators. Reporting helps to develop strategies to improve defense barriers during healthcare procedures, as well as institutional protocols aimed at patient safety and preventing new incidents.

Therefore, in order to encourage spontaneous incidents reporting, the following strategies were proposed: 1) brief and in loco educational interventions emphasizing the flow of reports in the institution, which would elucidate what to report as well as when and how to file one; 2) simplification and unification of the reporting form in order to allow patient identification, description of the incident, and input data of the incident; 3) deployment of institutional risk management policies with clearly defined positions, assignments, and responsibility; 4) employment of a professional to collect the reports and to follow up on the cases; and 5) feedback on the results obtained from the incident reports.

\section{DISCUSSION}

According to the perceptions of health professionals, a new barrier observed is the lack of accountability among health professionals according to the culture of reporting. However, after 40 years of the events reported ${ }^{(11)}$, four of them remain: guilt, indifference, diffidence, and ignorance. Data show the need to change the misunderstanding that only serious incidents should be reported, that incidents reporting is not a priority in clinical routine, and that the intention is to establish blame. Therefore, strategies to stimulate reporting should clarify the meaning of incident reports in the context of risk management and patient safety. Feasible and cost-effective methods have been proposed in other hospitals ${ }^{(12)}$.

Our results matched with the findings of a systematic review $^{(7)}$, which also demonstrated that ignorance, diffidence, and indifference are the principal causes of underreporting. Although the review included articles with cross-sectional design, the authors suggested that lack of knowledge about reporting is an important factor that hinders adherence to risk management practices. The authors also highlight the need of qualitative approaches to identity new barriers and strategies related to incidents reports. Our study allows identifying that lack of responsibility of health professionals is a problem to implement a culture of reporting in health institutions that was not observed with other methods.

However, our data show that knowledge per se is insufficient to promote changes in attitude and behavior. The same paradox was noticed in Canada ${ }^{(13)}$. Even if there is awareness about the importance of generating alerts, improving the process, and preventing new adverse reactions, these advantages do not encourage professionals to report them. This phenomenon can be explained by the effectiveness of educational interventions over time. After the interventions, the rate of adverse event reporting is enhanced for four months ${ }^{(8,14-15)}$. Therefore, periodic interventions should be performed to keep professionals motivated. However, 
when different methods were applied to improve the report of adverse drug reactions, it was observed that $10.5 \%$ of them were still unreported ${ }^{(9)}$, despite the multifaceted educational intervention ${ }^{(8)}$. Therefore, incentives are needed for the development of strategies to improve the skills of professionals regarding the true meaning of adverse event reporting in the context of patient care and the evaluation of health technologies. This would enable cultural changes and redefine the expectations about risk management ${ }^{(12)}$.

To achieve these goals, the strategies listed by hospital staff were brief, decentralized, and in loco educational interventions. This goes against the classical models of teaching and learning, in which knowledge is transferred passively through lectures. According to subjects, interventions could be performed in their own work environments to demonstrate the impact of incidents reported to health establishments and give guidance for filling out notification forms. The form should be reworded to allow agility and prioritization of the notification. It was suggested that a unified electronic instrument should be established for incident reporting, in which it would be possible to identify the incident, patient, and date of input. This would help to minimize the barrier of indifference due to a lack of time and the avoidance of bureaucratic paperwork.

The adoption of simplified forms may help with quantitative aspects, but it may be associated with incomplete information. The deployment of institutional risk management policies with definitions of activities and responsibilities could help to overcome this issue, since financial incentives fail to increase adherence to monitoring ${ }^{(16)}$.

Therefore, a professional could be designated to collect reports and to promote the follow up of each case in order to increase the quality of information and contribute to causality assessment.An on-site professional dedicated to reporting and education could contribute to improving risk management ${ }^{(13)}$.
Furthermore, feedback on the results arising from spontaneous reports should be provided to health professionals to increase adherence to the voluntary monitoring of healthcare procedures. Owing to underreporting of adverse events is associated with low use of technology ${ }^{(17)}$, alerts generated by health professionals should be published in 1) smartphone applications (after prior authorization by the employee), 2) institutional bulletins on patient safety, or 3) the homepage and official social networks of the health facility so that the information can be accessed by anyone who is interested ${ }^{(18)}$.

Finally, further studies should be carried out to assess whether the proposed interventions are effective in changing the behaviors and attitudes of professionals as well as prioritizing and speeding up risk communication in the hospital and improve the culture of reporting.

Limitations of the study: as a qualitative study, the results might not be reproducible in other settings or expanded beyond the subjects involved. However, it provides a clear picture that could benefit the present hospital practice.

\section{CONCLUSION}

Complacency, fear of litigation, ambition to publish, and ignorance are barriers to overcome which had hindered incidents reporting. However, lack of accountability of health professionals is a new factor related to underreporting. Knowledge of the importance of incidents reporting is considered a motivation for increasing the adherence of professionals to monitoring, but it is insufficient to increase attitude. Therefore, strategies proposed to enhance spontaneous incident monitoring are establishment of minimal criteria to report which could allow traceability by a professional or risk management team who will improve the quality of the information; and the tool of report be incorporated in the instrument applied by health professionals during their assistance in clinical practice (without a new form which promote interruptions in healthcare).

\section{RESUMO}

Objetivo: Identificar as barreiras da subnotificação, os fatores que motivam o relato e as estratégias para promover os registros de incidentes. Método: Por meio de rodas de conversas e a presença de um mediador, a equipe multidisciplinar do hospital, composta por 65 profissionais, foi estimulada a falar sobre tema. Resultado: Complacência e ambição são barreiras superadas. Falta de responsabilidade sobre notificação foi a nova barreira observada. Há uma crença de que apenas a enfermagem é responsável pela notificação. Conclusão: As estratégias para motivar os registros foram retornos das notificações relatadas (feedback), intervenções educativas na equipe de saúde, ferramentas simplificadas para notificação (manual ou eletrônica), com informações mínimas necessárias para a equipe de saúde otimizar o processo e o tempo de notificação. Para a garantia da qualidade do relato, a equipe de gerenciamento da segurança poderia melhorar ou complementar o relato.

\section{DESCRITORES}

Efeitos Colaterais e Reações Adversas Relacionados a Medicamentos; Atitude do Pessoal de Saúde; Segurança do Paciente; Gestão da Segurança; Sistemas de Notificação de Reações Adversas a Medicamentos; Farmacovigilância.

\section{RESUMEN}

Objetivo: Identificar las barreras de la subnotificación, los factores que motivan el relato y las estrategias para promover los registros de incidentes. Método: Mediante ruedas de conversación y la presencia de un mediador, el equipo multidisciplinario del hospital, compuesto de 65 profesionales, fue estimulado a hablar acerca del tema. Resultado: Complacencia y ambición son barreras superadas. Falta de responsabilidad acerca de la notificación fue la nueva barrera observada. Existe una creencia de que solo la enfermería es responsable de la notificación. Conclusión: Las estrategias para motivar los registros fueron retornos de las notificaciones relatadas (feedback), intervenciones educativas en el equipo sanitario, herramientas simplificadas para notificación (manual o electrónica), con informaciones mínimas necesarias para que el equipo sanitario optimice el proceso y el tiempo de notificación. Para la garantía de la calidad del relato, el equipo de gestión de la seguridad podría mejorar o complementar el relato.

\section{DESCRIPTORES}

Efectos Colaterales y Reacciones Adversas Relacionados con Medicamentos; Actitud del Personal de Salud; Seguridad del Paciente; Gestión de la Seguridad; Sistemas de Registro de Reacción Adversa a Medicamentos; Farmacovigilancia. 


\section{REFERENCES}

1. World Health Organization. Conceptual framework for the international classification for patient safety. Version 1.1 [Internet]. Geneva: WHO; 2009 [cited 2017 Jan 28]. Available from: http://www.who.int/patientsafety/implementation/taxonomy/icps_technical_report_en.pdf

2. Iedema R, Flabouris A, Grant S, Jorm C. Narrativizing errors of care: critical incident reporting in clinical practice. Soc Sci Med. 2006;62(1):134-44.

3. Howe CL. A review of the Office of Inspector General's reports on adverse event identification and reporting. J Healthc Risk Manag 2011;30(4):48-54. DOI: 10.1002/jhrm.20068

4. Howell AM, Burns EM, Bouras G, Donaldson LJ, Athanasiou T, Darzi A. Can patient safety incident reports be used to compare hospital safety? Results from a quantitative analysis of the English national reporting and learning system data. PLoS One [Internet]. 2015 [cited 2017 Jan 28];10(12):e0144107. Available from: https://www.ncbi.nlm.nih.gov/pmc/articles/PMC4674095/

5. Noble DJ, Pronovost PJ. Underreporting of patient safety incidents reduces health care's ability to quantify and accurately measure harm reduction. J Patient Saf. 2010;6(4):247-50.

6. Throckmorton T, Etchegaray J. Factors affecting incident reporting by registered nurses: the relationship of perceptions of the environment for reporting errors, knowledge of the nursing practice act, and demographics on intent to report errors. J Perianesth Nurs. 2007;22(6):400-12.

7. Varallo FR, Guimarães SOP, Abjaude SAR, Mastroianni PC. Causes for the underreporting of adverse drug events by health professionals: a systematic review. Rev Esc Enferm USP [Internet]. 2014 [cited 2017 Jan 28];48(4):739-47. Available from: http://www.scielo.br/pdf/reeusp/ v48n4/0080-6234-reeusp-48-04-739.pdf

8. Varallo FR, Planeta CS, Mastroianni PC. Effectiveness of pharmacovigilance : multifaceted educational intervention related to the knowledge, skills and attitudes of multidisciplinary hospital staff. Clinics (Sao Paulo) [Internet]. 2017 [cited 2017 June 20];72(1):51-7. Available from: https://www.ncbi.nlm.nih.gov/pmc/articles/PMC5251201/

9. Varallo FR, Dagli-Hernandez C, Pagotto C, Nadai TR, Herdeiro MT, Mastroianni PC. Confounding variables and the performance of triggers in detecting unreported adverse drug reactions. Clin Ther. 2017;39(4):686-96. DOI: 10.1016/j.clinthera.2016.11.005

10. Clark JP. How to peer review a qualitative manuscript. In: Godlee F, JeffersonT, editors. Peer review in health sciences. London: BMJ Books; 2003. p. 219-35.

11. Inman WHW. Assessment drug safety problems. In: Gent M, Shigmatsu I, editors. Epidemiological issues in reported drug-induced illnesses. Honolulu, Ontario: McMaster University; 1976. p. 17-24.

12. Bäckström M, Mjörndal T, Dahlqvist R, Nordkvist-Olsson T. Attitudes to reporting adverse drug reactions in northern Sweden. Eur J Clin Pharmacol. 2000;56(9-10):729-32.

13. Nichols V, Thériault-Dubé I, Touzin J, Delisle JF, Lebel D, Bussières JF, et al. Risk perception and reasons for noncompliance in pharmacovigilance: a qualitative study conducted in Canada. Drug Saf. 2009;32(7):579-90. DOI: 10.2165/00002018-200932070-00004

14. Figueiras A, Herdeiro MT, Polónia J, Gestal-Otero JJ. An educational intervention to improve physician reporting of adverse drug reactions: a cluster-randomized controlled trial. JAMA [Internet]. 2006 [cited 2017 Jan 28]; 296:1086-93. Available from: http://jamanetwork.com/ journals/jama/fullarticle/203253 DOI 10.1001/jama.296.9.1086

15. Ribeiro-Vaz I, Herdeiro MT, Polónia J, Figueiras A. Strategies to increase the sensitivity of pharmacovigilance in Portugal. Rev Saúde Pública [Internet]. 2011 [cited 2017 Jan 28]; 45(1):129-35. Available from: http://www.scielo.br/pdf/rsp/v45n1/en_1771.pdf

16. Cereza G, Agustí A, Pedrós C, Vallano A, Aguilera C, Danés I, et al. Effect of an intervention on the features of adverse drug reactions spontaneously reported in a hospital. Eur J Clin Pharmacol. 2010;66(9):937-45. DOI: 10.1007/s00228-010-0856-8

17. Edwards R. An agenda for UK clinical pharmacology: pharmacovigilance. Br J Clin Pharmacol. 2012;73(6):979-82. DOI: 10.1111/j.13652125.2012.04249.x

18. Knezevic MZ, Bivolarevic IC, Peric TS, Jankovic SM. Using Facebook to increase spontaneous reporting of adverse drug reactions. Drug Saf. 2011;34(4):351-2. DOI: 10.2165/11590110-000000000-00000

Coordenação de Aperfeiçoamento de Pessoal de Nível Superior (CAPES). Scholarship (PDSE) grant no. 014301/201300. Fundação de Amparo à Pesquisa do Estado de São Paulo (FAPESP). Project under grant \#2013/10263-9. Programa de Apoio ao Desenvolvimento Científico, Faculty of Pharmaceutical Sciences, Universidade Estadual Paulista. 